\title{
Mortality risk after transcatheter aortic valve implantation: analysis of the predictive accuracy of the Transcatheter Valve Therapy registry risk assessment model
}

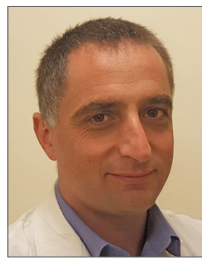

Pablo Codner ${ }^{1,2 *}$, MD; Waqas Malick¹, MD; Remi Kouz ${ }^{1}$, MD, MSc; Amisha Patel ${ }^{1}$, MD; Cheng-Han Chen ${ }^{1}, \mathrm{MD}$, PhD; Juan Terre ${ }^{1}$, MD; Uri Landes², MD; Torsten P. Vahl'1, MD; Isaac George ${ }^{1,3}$, MD; Tamim Nazif ${ }^{1}, \mathrm{MD}$; Ajay J. Kirtane ${ }^{1}$, MD, SM; Omar K. Khalique ${ }^{1}, \mathrm{MD}$; Rebecca T. Hahn¹, MD; Martin Leon ${ }^{1}$, MD; Susheel Kodali¹, MD

1. Department of Medicine, Division of Cardiology, NewYork-Presbyterian Hospital/Columbia University Medical Center, New York, NY, USA; 2. Department of Medicine, Division of Cardiology, Rabin Medical Center, Petah Tikva, and Sackler School of Medicine Tel Aviv University, Tel Aviv, Israel; 3. Department of Surgery, Division of Cardiothoracic Surgery, NewYorkPresbyterian Hospital, Columbia College of Physicians and Surgeons, New York, NY, USA

This paper also includes supplementary data published online at: http://www.pcronline.com/eurointervention/137th_issue/72

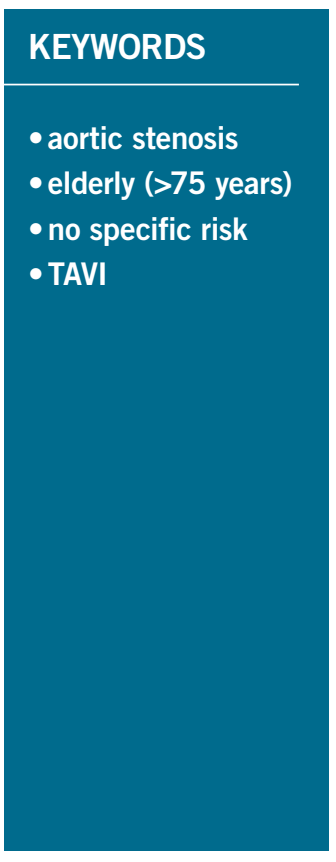

\section{Abstract}

Aims: The risk assessment tools currently used to predict mortality in transcatheter aortic valve implantation (TAVI) were designed for patients undergoing cardiac surgery. We aimed to assess the accuracy of the TAVI dedicated risk score in predicting mortality outcomes.

Methods and results: Consecutive patients $(n=1,038)$ undergoing TAVI at a single institution from 2014 to 2016 were included. The ACC/TVT registry mortality risk score, the STS-PROM score and the EuroSCORE II were calculated for all patients. In-hospital and 30-day all-cause mortality rates were $1.3 \%$ and $2.9 \%$, respectively. The ACC/TVT risk stratification tool scored higher for patients who died in-hospital than for those who survived the index hospitalisation ( $6.4 \pm 4.6$ vs. $3.5 \pm 1.6, p=0.03$, respectively). The ACC/TVT score showed a high level of discrimination, C-index for in-hospital mortality $0.74,95 \% \mathrm{CI}$ : (0.59-0.88). There were no significant differences between the performance of the ACC/TVT registry risk score, the EuroSCORE II and the STS-PROM score for in-hospital and 30-day mortality rates.

Conclusions: The ACC/TVT registry risk model is a dedicated tool to aid in the prediction of in-hospital mortality risk after TAVI.

\footnotetext{
* Corresponding author: Structural Heart Diseases, New York Presbyterian Hospital, 161 Fort Washington Avenue, 6th Floor, New York, NY 10032,USA. E-mail: pablocodner@hotmail.com
} 


$\begin{array}{ll}\begin{array}{ll}\text { Abbreviations } \\ \text { ACC/TVT }\end{array} & \begin{array}{l}\text { American College of Cardiology/Transcatheter Valve } \\ \text { Therapy }\end{array} \\ \text { AS } & \text { aortic stenosis } \\ \text { CI } & \text { confidence interval } \\ \text { GFR } & \text { glomerular filtration rate } \\ \text { LVEF } & \text { left ventricular ejection fraction } \\ \text { SAVR } & \text { surgical aortic valve replacement } \\ \text { STS-PROM } & \text { Society of Thoracic Surgeons - predicted risk of } \\ & \text { mortality } \\ \text { TAVI } & \text { transcatheter aortic valve implantation } \\ \text { VARC-2 } & \text { Valve Academic Research Consortium-2 }\end{array}$

\section{Introduction}

Transcatheter aortic valve implantation (TAVI) has emerged as an option for patients with severe aortic stenosis (AS) at elevated risk for surgical aortic valve replacement $(\mathrm{SAVR})^{1-3}$. In clinical practice, the Heart Team estimates risk for SAVR/TAVR utilising a combination of clinical judgement, frailty indices, and various surgical risk calculators such as the Society of Thoracic Surgeons - predicted risk of mortality (STS-PROM) score, the logistic EuroSCORE and the EuroSCORE $\mathrm{II}^{4-7}$. However, these risk scores, designed for surgical risk assessment, have not been validated in transcatheter interventions and their ability to predict risk for TAVI is unclear ${ }^{8,9}$. Recently, a dedicated TAVI risk model has been developed based on the data from the American College of Cardiology (ACC)/Transcatheter Valve Therapy (TVT) registry ${ }^{10}$. The aim of the present study was to compare the accuracy of the STS-PROM, EuroSCORE II, and ACC/TVT risk scores in predicting outcomes from a large population of TAVI patients.

\section{Methods}

From January 2014 to November 2016 all patients with severe AS who underwent TAVI at our institution $(n=1,038)$ were identified. Decisions regarding risk and candidacy for TAVI were made by a dedicated Heart Team.

Severe AS was defined as a valvular orifice area $<1.0 \mathrm{~cm}^{2}$ or $<0.6 \mathrm{~cm}^{2} / \mathrm{m}^{2}$ and/or mean pressure gradient $>40 \mathrm{mmHg}$ and/or jet velocity $>4.0 \mathrm{~m} / \mathrm{s}$. Selected patients with discordant echocardiographic findings underwent dobutamine echocardiography.

Patients were assessed by echocardiography, coronary angiography, and gated cardiac computed tomography. If vascular anatomy was unsuitable for a transfemoral approach alternative accesses were considered.

The ACC/TVT risk score, the STS-PROM score, and the EuroSCORE II were calculated for all patients ${ }^{11-13}$. Variables and endpoints of the ACC/TVT risk prediction tool, the STS-PROM score and the EuroSCORE II are presented in Supplementary Table 1. Events were collected in a dedicated database during the index hospitalisation, at 30-day followup and at one year. Endpoints were adjudicated according to the Valve Academic Research Consortium-2 (VARC-2) definitions ${ }^{14}$. The Columbia University Institutional Review Board approved the retrospective chart reviews of all patients and waived individual patient consent.

\section{STATISTICAL ANALYSIS}

The primary outcomes were in-hospital and 30-day all-cause mortality. Descriptive data are presented as means and standard deviations for continuous data or frequencies and percentages for categorical data. For univariate analysis, t-tests were used to compare the continuous variables and Pearson's chi-square tests were performed for categorical variables to determine the associations between in-hospital mortality and/or 30-day mortality with baseline demographic, echocardiographic and TAVI procedural characteristics.

Discriminatory abilities of the models were assessed using the $\mathrm{C}$-index. The $\mathrm{C}$-index ranges from 0 to 1 , with higher values indicating better discrimination. A non-parametric DeLong method was used through the ROCCONTRAST option in PROC LOGISTIC (SAS Institute Inc., Cary, NC, USA) to compare two ROC curves. We examined the predictive accuracy of the ACC/TVT risk score vs. EuroSCORE II, ACC/TVT registry score vs. STS-PROM score, EuroSCORE II vs. STS-PROM score for in-hospital mortality and 30-day mortality using the DeLong method. Calibration of the models was evaluated using the Hosmer-Lemeshow $\chi^{2}$ statistic goodness-of-fit test, which compares observed and predicted outcomes over deciles of risk and also the observed probability with the expected probability within each decile, with a value $<0.05$ indicating significant difference in expected versus observed mortality. Analyses were conducted using SAS software, version 9.4 (SAS Institute Inc.). Statistical significance was set at $\mathrm{p}<0.05$.

\section{Results}

We analysed the outcomes of 1,038 consecutive patients (female 49.6\%) treated with TAVI between January 2014 and December 2016. In-hospital and 30-day survival status was available in $100 \%$ and $99.3 \%$ of patients, respectively. In-hospital and 30-day mortality rates were $1.34 \%$ and $2.9 \%$, respectively. Baseline characteristics of survivors in comparison to non-survivors are presented in Table 1. In-hospital non-survivors were more likely to present with heart failure than in-hospital survivors (14 [100\%] vs. 817 [79.8\%], p=0.04). They also demonstrated higher rates of prior myocardial infarction (MI) (6 [42.8\%] vs. 162 [15.8\%], $\mathrm{p}=0.01)$, atrial fibrillation (10 [71.4\%] vs. $402[39.2 \%], \mathrm{p}=0.006)$ and chronic lung disease (7 [50\%] vs. 251 [24.5\%], p=0.02) than in-hospital survivors.

Baseline echocardiographic features are presented in Table 2. Survivors in comparison to non-survivors had higher left ventricular ejection fraction (LVEF) at baseline (55 $\pm 16 \%$ vs. $42 \pm 18 \%$; $\mathrm{p}=0.002)$ and at 30 -day follow-up $(55 \pm 15.5 \%$ vs. $45 \pm 18 \% ; 0.001)$ as well as lower rates of right ventricular dysfunction (at baseline, $224[22 \%]$ vs. 7 [50\%], p=0.01, and at 30 days, 215 [22\%] vs. 13 [43\%], $\mathrm{p}=0.01$ ) (Table 2). Non-transfemoral access was associated with higher mortality rates $(48[4.6 \%]$ vs. $6[42.8 \%], p<0.001$, and 
Table 1. Baseline characteristics.

\begin{tabular}{|c|c|c|c|c|c|c|c|}
\hline & $\begin{array}{c}\text { All patients } \\
(\mathrm{N}=1,038)\end{array}$ & $\begin{array}{c}\text { In-hospital } \\
\text { survivors } \\
(n=1,024)\end{array}$ & $\begin{array}{c}\text { In-hospital } \\
\text { non-survivors } \\
(n=14)\end{array}$ & $p$-value & $\begin{array}{l}\text { 30-day } \\
\text { survivors } \\
(n=984)\end{array}$ & $\begin{array}{c}\text { 30-day } \\
\text { non-survivors } \\
(n=30)\end{array}$ & $p$-value \\
\hline Age, years & $83.2 \pm 7.9$ & $83.2 \pm 7.9$ & $85.1 \pm 8.8$ & 0.37 & $83.1 \pm 8.0$ & $84.8 \pm 7.2$ & 0.25 \\
\hline Female & $515(50)$ & $509(50)$ & $6(43)$ & 0.61 & $488(50)$ & $12(40)$ & 0.30 \\
\hline Body mass index, $\mathrm{kg} / \mathrm{m}^{2}$ & $26.8 \pm 5.9$ & $26.9 \pm 5.9$ & $26.5 \pm 5.5$ & 0.82 & $26.8 \pm 5.9$ & $26.8 \pm 4.5$ & 0.99 \\
\hline ACC/TVT risk score & $3.6 \pm 1.7$ & $3.5 \pm 1.0$ & $6.4 \pm 4.6$ & 0.03 & $3.5 \pm 1.6$ & $5.0 \pm 3.5$ & 0.02 \\
\hline EuroSCORE II & $6.1 \pm 5.4$ & $6.0 \pm 5.3$ & $13.2 \pm 10.8$ & 0.03 & $6.0 \pm 5.2$ & $11.1 \pm 9.8$ & 0.01 \\
\hline STS-PROM score & $6.7 \pm 4.8$ & $6.6 \pm 4.6$ & $14.4 \pm 12.4$ & 0.03 & $6.6 \pm 4.6$ & $11.0 \pm 9.6$ & 0.01 \\
\hline CHF prior two weeks & $831(80)$ & $817(79.8)$ & $14(100)$ & 0.04 & $803(79.6)$ & $27(80)$ & 0.07 \\
\hline Prior myocardial infarction & $168(16.2)$ & $162(15.8)$ & $6(42.8)$ & 0.01 & $151(14.9)$ & $9(30)$ & 0.02 \\
\hline Prior $\mathrm{PCl}$ & $306(29.4)$ & $301(29.4)$ & $5(35.7)$ & 0.19 & 302 (29.9) & $8(26.7)$ & 0.15 \\
\hline Atrial fibrillation & $412(39.7)$ & $402(39.2)$ & $10(71.4)$ & 0.006 & $393(38.9)$ & $19(63.3)$ & 0.004 \\
\hline Cerebrovascular disease & $176(16.9)$ & $173(17)$ & $3(21.4)$ & 0.23 & $170(16.8)$ & $6(20)$ & 0.16 \\
\hline Peripheral arterial disease & $163(15.7)$ & $160(15.6)$ & $3(21.4)$ & 0.21 & $160(15.9)$ & $6(20)$ & 0.15 \\
\hline Diabetes mellitus & $316(30.4)$ & $309(30.1)$ & $7(50)$ & 0.06 & $306(30.6)$ & $11(36.6)$ & 0.11 \\
\hline Hypertension & $961(92.6)$ & $947(92.4)$ & $14(100)$ & 0.33 & $929(92.1)$ & $28(93.3)$ & 0.28 \\
\hline Dyslipidaemia & $846(81.5)$ & $834(81.4)$ & $12(85.7)$ & 0.26 & $812(80.5)$ & $24(80)$ & 0.17 \\
\hline Chronic lung disease & $258(24.9)$ & $251(24.5)$ & $7(50.0)$ & 0.02 & $246(24.4)$ & $14(46.6)$ & 0.005 \\
\hline Glomerular filtration rate, $\mathrm{ml} / \mathrm{min} / \mathrm{m}^{2}$ & $49.4 \pm 23.9$ & $49.5 \pm 23.8$ & $51.2 \pm 24.6$ & 0.41 & $49.2 \pm 23.9$ & $50.3 \pm 23.5$ & 0.37 \\
\hline Pre-TAVI creatinine, mg/dl & $1.3 \pm 0.9$ & $1.3 \pm 0.9$ & $1.39 \pm 0.8$ & 0.75 & $1.3 \pm 0.9$ & $1.5 \pm 0.9$ & 0.20 \\
\hline CKD stage 3 & $514(49.5)$ & $508(49.6)$ & $6(43)$ & 0.63 & $494(50.2)$ & $14(46.6)$ & 0.52 \\
\hline CKD stage 4 & $98(9.4)$ & $96(9.4)$ & $2(14.2)$ & 0.38 & $80(8.1)$ & $4(13.3)$ & 0.23 \\
\hline Renal replacement therapy & $27(2.6)$ & $24(2.2)$ & $3(21.4)$ & 0.004 & $21(2.0)$ & $4(13.3)$ & 0.005 \\
\hline
\end{tabular}

44 [4.4\%] vs. 10 [33.3\%], $\mathrm{p}=0.04)$, for survivors vs. non-survivors during hospitalisation and at 30-day follow-up, respectively. Major vascular complications were significantly higher in non-survivors in comparison to survivors (4 [28.5\%] vs. 20 [1.9\%], p<0.001 for in hospital non-survivors vs. survivors, respectively) (Table 3).

Mean ACC/TVT registry risk score and EuroSCORE II predicted a relatively high in-hospital mortality, $3.6 \pm 1.7 \%$ and $6.1 \pm 5.4 \%$, respectively, in comparison to the $1.3 \%$ in-hospital mortality registered among our cohort of patients. Predicted 30-day mortality rates according to STS-PROM score were $6.7 \pm 4.8 \%$ in contrast to the lower actual 30-day mortality rates of $2.9 \%$. The ACC/TVT risk stratification tool scored higher for patients who died in hospital than for those who survived (6.4 \pm 4.6 vs. $3.5 \pm 1.6$, $\mathrm{p}=0.03$, respectively).

The ACC/TVT registry risk score showed a high level of discrimination (C-index for in-hospital mortality area under the curve [AUC] 0.74, 95\% confidence interval [CI]: 0.59-0.88) (Figure 1A). The C-index statistics for in-hospital mortality of the EuroSCORE II and

Table 2. Baseline echocardiographic characteristics.

\begin{tabular}{|c|c|c|c|c|c|c|c|}
\hline & $\begin{array}{l}\text { All patients } \\
(N=1,038)\end{array}$ & $\begin{array}{c}\text { In-hospital } \\
\text { survivors } \\
(n=1,024)\end{array}$ & $\begin{array}{c}\text { In-hospital } \\
\text { non-survivors } \\
(n=14)\end{array}$ & $p$-value & $\begin{array}{l}\text { 30-day } \\
\text { survivors } \\
(n=984)\end{array}$ & $\begin{array}{c}\text { 30-day } \\
\text { non-survivors } \\
(n=30)\end{array}$ & $p$-value \\
\hline Left ventricular ejection fraction $\%$ & $54.7 \pm 15.7$ & $54.9 \pm 15.6$ & $41.6 \pm 17.7$ & 0.002 & $55.0 \pm 15.5$ & $45.4 \pm 18.2$ & 0.001 \\
\hline Right ventricular dysfunction & $231(22)$ & $224(22)$ & $7(50)$ & 0.01 & $215(22)$ & $13(43)$ & 0.01 \\
\hline Mitral regurgitation $\geq$ moderate & $246(24)$ & $238(23)$ & $8(57)$ & 0.01 & $233(24)$ & $13(43)$ & 0.01 \\
\hline Peak aortic valve gradient, $\mathrm{mmHg}$ & $73.7 \pm 24.4$ & $73.9 \pm 24.3$ & $62.4 \pm 29.2$ & 0.08 & $74.0 \pm 24.5$ & $66.6 \pm 23.4$ & 0.10 \\
\hline Mean aortic valve gradient, $\mathrm{mmHg}$ & $40.5 \pm 14.3$ & $40.6 \pm 14.3$ & $33.9 \pm 16.8$ & 0.08 & $40.6 \pm 14.4$ & $36.3 \pm 13.6$ & 0.11 \\
\hline Peak aortic valve velocity, $\mathrm{m} / \mathrm{s}$ & $4.2 \pm 0.7$ & $4.2 \pm 0.7$ & $3.8 \pm 1.0$ & 0.15 & $4.2 \pm 0.7$ & $4.0 \pm 0.8$ & 0.09 \\
\hline Calculated aortic valve area, $\mathrm{cm}^{2}$ & $0.8 \pm 0.8$ & $0.8 \pm 0.8$ & $0.8 \pm 0.2$ & 0.71 & $0.8 \pm 0.8$ & $0.8 \pm 0.2$ & 0.81 \\
\hline Low-gradient severe aortic stenosis & $276(27)$ & $272(27)$ & $4(29)$ & 0.89 & $267(27)$ & $9(30)$ & 0.62 \\
\hline
\end{tabular}


Table 3. Transcatheter aortic valve implantation procedural characteristics.

\begin{tabular}{|c|c|c|c|c|c|c|c|}
\hline & $\begin{array}{l}\text { All patients } \\
(\mathrm{N}=1,038)\end{array}$ & $\begin{array}{l}\text { In-hospital } \\
\text { survivors } \\
(n=1,024)\end{array}$ & $\begin{array}{c}\text { In-hospital } \\
\text { non-survivors } \\
(n=14)\end{array}$ & $p$-value & $\begin{array}{l}\text { 30-day } \\
\text { survivors } \\
(n=994)\end{array}$ & $\begin{array}{c}\text { 30-day } \\
\text { non-survivors } \\
(n=30)\end{array}$ & $p$-value \\
\hline Valve-in-valve & $46(4.4)$ & $45(4.4)$ & $1(7.1)$ & 0.34 & $39(4.4)$ & $2(7.1)$ & 0.23 \\
\hline Transfemoral access & $984(94.8)$ & $976(95.3)$ & $8(57.1)$ & & $950(95.6)$ & $26(86.7)$ & \\
\hline Non-transfemoral access & $54(5.2)$ & $48(4.6)$ & $6(42.8)$ & $<0.001$ & $44(4.4)$ & $10(33.3)$ & 0.04 \\
\hline Edwards valve devices & $714(68.8)$ & & & & & & \\
\hline Medtronic valve devices & $320(30.8)$ & & & & & & \\
\hline Minor vascular complication & $411(39.6)$ & 406 (39.6) & $5(35.7)$ & 0.20 & $391(39.7)$ & $10(33.3)$ & 0.12 \\
\hline Major vascular complication & $24(2.3)$ & $20(1.9)$ & $4(28.5)$ & $<0.001$ & $16(1.6)$ & $4(13.3)$ & 0.003 \\
\hline Need for permanent pacemaker & $137(13.2)$ & $136(13.3)$ & $1(7.1)$ & 0.30 & $132(13.4)$ & $4(13.3)$ & 0.21 \\
\hline Need for renal replacement treatment & $6(0.58)$ & $4(0.39)$ & 2 (14.3) & 0.002 & $1(0.1)$ & $3(10)$ & $<0.001$ \\
\hline Any bleeding & $192(18.5)$ & 183 (17.9) & 9 (64.3) & $<0.001$ & $161(16)$ & $13(43.3)$ & $<0.001$ \\
\hline
\end{tabular}

Values are presented as mean \pm standard deviation (SD) or number (\%). Outcomes were adjudicated using the Valve Academic Research Consortium-2 (VARC-2) criteria.

30-day mortality of the STS-PROM score are shown in Figure 1A and Figure 1B, respectively. There were no significant differences in the predictive performances of the ACC/TVT registry risk score, the EuroSCORE II and the STS-PROM score for in-hospital and/or 30-day mortality rates. A comparison of the discriminative performance of the ACC/TVT registry risk score vs. the EuroSCORE II vs. the STS-PROM score for in-hospital and 30-day mortality is presented in Figure 1A and Figure 1B, respectively.

The calibration of the ACC/TVT risk prediction tool was accurate for in-hospital and 30-day mortality (Hosmer and Lemeshow goodness-of-fit 0.78 , intercept $-6.14[-7.24,-5.04], \mathrm{p}<0.0001$ for in-hospital mortality and Hosmer and Lemeshow goodnessof-fit 0.84 , intercept $-4.71[-5.45,-3.96], \mathrm{p}<0.0001$ for 30 -day mortality) (Table 4). The ACC/TVT registry risk score showed a calibration slope of 0.4 and 0.3 for in-hospital and 30-day mortality, respectively. The calibration slope of the EuroSCORE II was 0.1 for in-hospital mortality and 0.09 for 30-day mortality, and the calibration slope of the STS-PROM score was 0.11 and 0.09 for in-hospital and 30-day mortality, respectively. The higher calibration slope of the ACC/TVT registry provides a better

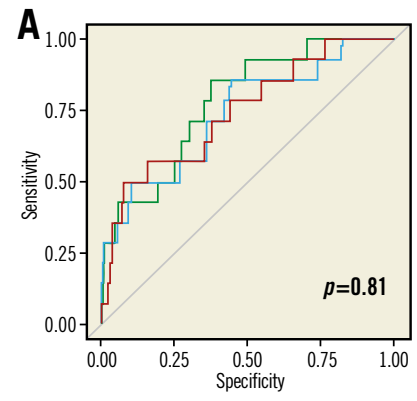

ROC curve (area; $95 \% \mathrm{Cl}$ )

- ACC/TVT risk score (0.738; 95\% Cl: 0.59-0.89) —EurOSCORE II (0.746; $95 \% \mathrm{Cl}: 0.61-0.89)$

- STS-PROM score (0.784; $95 \% \mathrm{Cl}$ : 0.67-0.89)

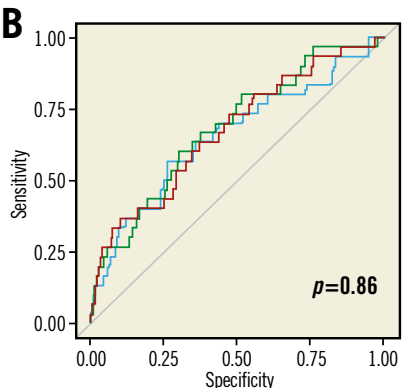

ROC curve (area; 95\% Cl)

—ACC/TVT risk score $(0.655 ; 95 \% \mathrm{Cl}: 0.54-0.76$ —EurOSCORE II (0.674; $95 \% \mathrm{Cl}: 0.57-0.77)$

—STS-PROM score (0.692; 95\% Cl: 0.58-0.78)
Figure 1. Comparison of the discrimination ability of the TVT registry risk score, EuroSCORE II, and STS-PROM score. A) In-hospital mortality. B) 30-day mortality.

sensitivity in comparison to the EuroSCORE II and the STSPROM score (Table 4). Dispersion graphs showing the correlation of the STS-PROM score and the EuroSCORE II to the ACC/TVT risk score are presented in Figure 2A and Figure 2B, respectively.

Table 4. Calibration of the ACC/TVT registry model, the EuroSCORE II and the STS-PROM score.

\begin{tabular}{|c|c|c|c|c|c|}
\hline & $\begin{array}{l}\text { Hosmer and Lemeshow } \\
\text { goodness-of-fit test } \mathrm{Pr}>\mathrm{chi}{ }^{2}\end{array}$ & Intercept & $p$-value & Slope & $p$-value \\
\hline \multicolumn{6}{|c|}{ ACC/TVT registry model } \\
\hline In-hospital mortality & 0.78 & $-6.14(-7.24,-5.04)$ & $<0.0001$ & $0.41(0.24,0.58)$ & $<0.0001$ \\
\hline 30-day mortality & 0.84 & $-4.71(-5.45,-3.96)$ & $<0.0001$ & $0.30(0.16,0.43)$ & $<0.0001$ \\
\hline \multicolumn{6}{|l|}{ EuroSCORE II } \\
\hline In-hospital mortality & 0.81 & $-5.16(-6.04,-4.44)$ & $<0.0001$ & $0.10(0.05,0.15)$ & $<0.0001$ \\
\hline 30-day mortality & 0.97 & $-4.19(-4.74,-3.65)$ & $<0.0001$ & $0.09(0.05,0.13)$ & $<0.0001$ \\
\hline \multicolumn{6}{|l|}{ STS-PROM score } \\
\hline In-hospital mortality & 0.24 & $-5.33(-6.14,-4.52)$ & $<0.0001$ & $0.11(0.06,0.16)$ & $<0.0001$ \\
\hline 30-day mortality & 0.65 & $-4.22(-4.78,-3.67)$ & $<0.0001$ & $0.09(0.05,0.13)$ & $<0.0001$ \\
\hline
\end{tabular}


A

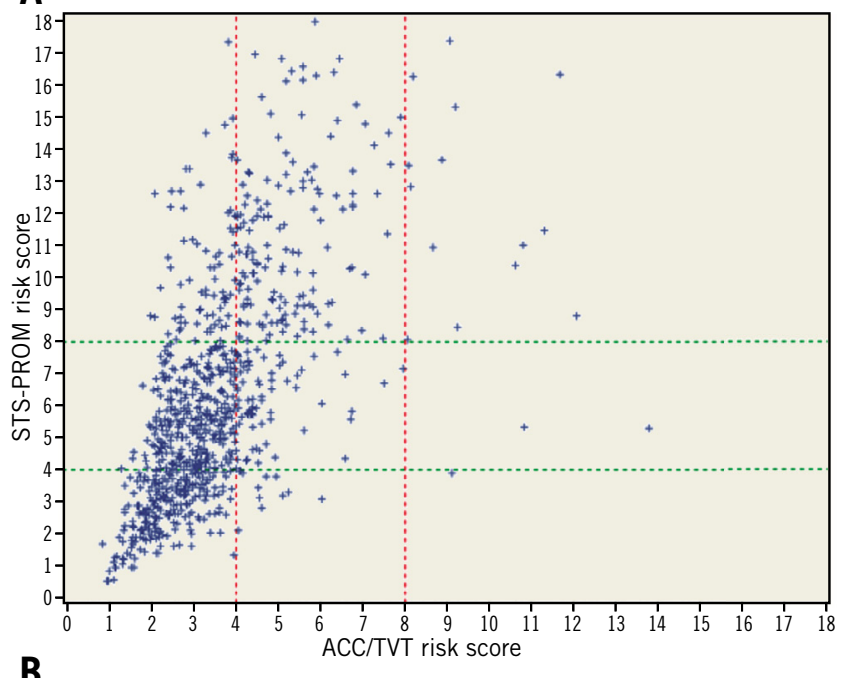

B

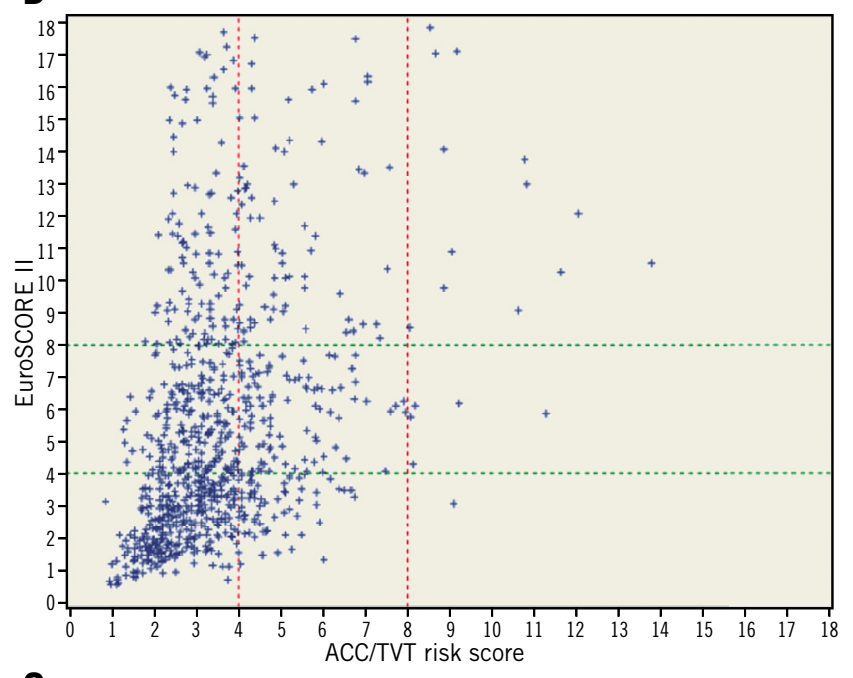

C

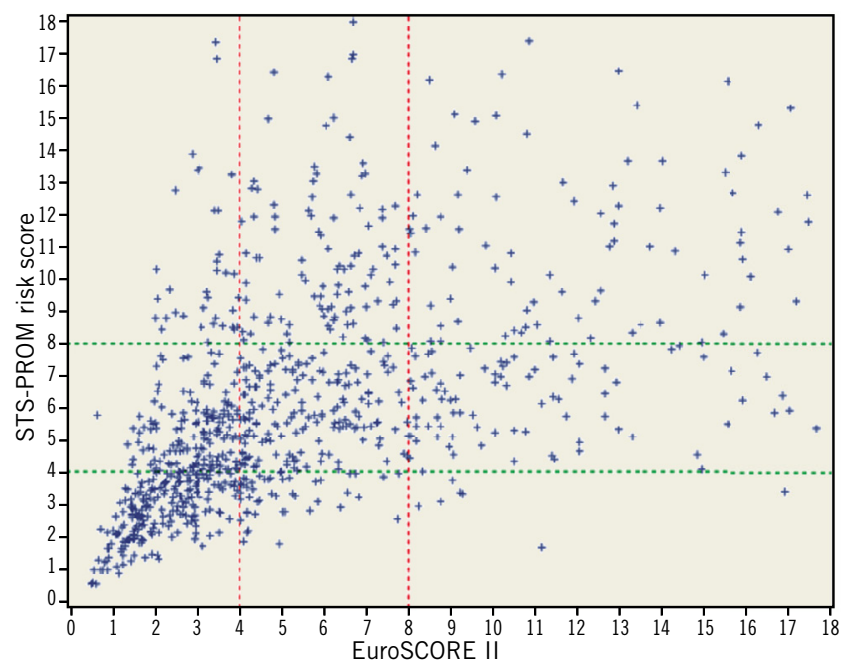

Figure 2. Comparison of the TVT registry risk score, EuroSCORE II, and STS-PROM risk score's calculated expected mortality. Panels $A$ and $B$ show that the EurOSCORE II and STS-PROM models' expected mortality was higher than that of the TVT registry model. Panel C shows that the EuroSCORE II and STS-PROM scores were more correlated.
The correlation of the STS-PROM score to the EuroSCORE II is presented in Figure 2C.

\section{Discussion}

This study sought to validate the STS/ACC TVT registry risk model for predicting in-hospital mortality in 1,038 patients who underwent TAVI between January 2014 and December 2016, and to compare the performance of this risk model to the performances of the STS-PROM and EuroSCORE II risk models for predicting mortality.

The primary findings are as follows. 1) The ACC/TVT performed as well as the STS-PROM score and EuroSCORE II, and there were no significant differences in the performance metrics of these models. 2) The ACC/TVT, STS-PROM and EuroSCORE II risk assessment tools predicted higher than the actual mortality rates. 3) Calibration was accurate for the three evaluated models with a higher calibration slope registered for the ACC/TVT. 4) Dispersion graphs demonstrated good correlation between the STS-PROM and the EuroSCORE II models but, when compared to the ACC/TVT registry model, both surgical models tended to place patients at higher risk than the ACC/TVT risk model. 5) Non-survivors had higher rates of LV dysfunction, right ventricular dysfunction, chronic lung disease, congestive heart failure, prior MI, atrial fibrillation and non-transfemoral access as well as higher rates of bleeding and major vascular complications.

This study demonstrated that the ACC/TVT registry risk model is equivalent to the STS-PROM score for predicting in-hospital mortality. The ACC/TVT registry model showed good calibration along with numerically (not statistically significant) higher discrimination than the STS-PROM model. However, as the ACC/ TVT registry model predicts in-hospital and the STS-PROM model predicts 30-day mortality, the two scores predict different parameters of the risk-benefit analysis. The EuroSCORE II, which is validated to predict in-hospital mortality, did not differ significantly from the ACC/TVT model.

Previous TAVI risk models have been developed ${ }^{15-18}$. Although reported to have good discrimination, they are limited by their small derivation cohorts. The ACC/TVT registry derived and validated its risk model in a population of 13,718 and 6,868 , respectively ${ }^{10}$.

Herein, patients underwent TAVI from January 2014 to November 2016, while the TVT database included procedures from January 2011 to February 2014. Therefore, our cohort of patients does not significantly overlap with the ACC/TVT registry. Patients treated recently probably received newer-generation devices and delivery catheters and were treated by operators with greater experience.

Shorter hospital stays in contemporary patients (as against derivation) may also affect in-hospital mortality figures. Future models should be called to look at mortality at specific time points (i.e., 30 days, one year, etc.).

In accordance with our findings, other studies also predicted higher than the actual mortality rates. In the PARTNER B trial, the average STS-PROM score for patients undergoing TAVI was $11.2 \%$, 
while actual in-hospital mortality was $1.7 \%$ and 30 -day mortality was $6.4 \%{ }^{1}$. This was also noted in the PARTNER A and in the more recent PARTNER 2 and SURTAVI trials studying patients at intermediate risk ${ }^{2,3,19}$. In our cohort, the average STS-PROM score and EuroSCORE II were 6.7 and $6.1 \%$, respectively, while actual mortality rates were $1.3 \%$ (in-hospital) and $2.9 \%$ (30 days). The ability of any risk score to predict mortality accurately in patients undergoing TAVI remains limited as the field rapidly evolves and mortality rates continue to decline. Our study showed that the ACC/TVT registry risk model, the STS-PROM score and the EuroSCORE II may already be dated.

The strength of the ACC/TVT risk model lies in the fact that it was derived and validated utilising patients undergoing TAVI, whereas the STS-PROM score and EuroSCORE II were developed using outcomes in patients undergoing cardiothoracic surgery ${ }^{4-7}$. Another strength of the model is its easy clinical applicability with only seven variables ${ }^{11}$. However, its limitations include absence of measurements of frailty; it is currently used to predict in-hospital mortality. A 30-day risk calculator is being developed and this will allow direct comparison between the STS-PROM and the ACC/TVT risk scores ${ }^{20}$.

This study also included dispersion graphs to provide a visual aid to assess the correlation among the three risk models. Patients located in the superior left and inferior right parts of the graphs showed poor correlation. The dispersion graphs show a correlation between the STS-PROM score and EuroSCORE II for most patients. When either of these is compared to the ACC/TVT registry risk model, the STS-PROM score and EuroSCORE II tend to score higher, and far more patients are located in the superior left part of the graph, indicating a higher score than by using the ACC/TVT registry risk score. These differences can be explained by the presence of certain variables in the surgical risk scores that are not included in the ACC/TVT registry risk model. Previous cardiothoracic surgery is of importance when considering surgical AVR and is included in the STS-PROM and EusoSCORE II calculators; however, patients undergoing TAVI do not face the same risk, as the procedure is minimally invasive, hence this variable is not included in the ACC/TVT registry risk calculator. Moreover, LVEF \%, peripheral artery disease, active endocarditis and other parameters are included in both surgically derived risk prediction tools but not included in the ACC/TVT registry risk model ${ }^{11-13}$.

\section{Limitations}

This is a single-centre study so generalisability is a limitation. Although we were able to include 1,038 patients, our population was still small compared to the original risk model derivation and validation cohort populations. In addition, the number of events was relatively low. Therefore, our ability to show differences among scores may be limited. However, our population was diverse and large enough to demonstrate good discrimination and to reassure that no significant differences exist among the risk models. Another limitation of our study was the exclusion of the frailty index. While the risk-benefit assessment for TAVI is still evolving, we should keep in mind that a sizeable group of patients does not fully benefit from the intervention in terms of quality-of-life measures. Future prediction scores should also focus on and facilitate identifying patients who would gain quality-of-life benefits from TAVI ${ }^{21}$.

Although we were able to show that the ACC/TVT registry risk model has slightly better discrimination than the STSPROM risk model, this conclusion is limited because clinical practice includes both the STS-PROM risk score and frailty index in the risk-benefit analysis discussion. Lastly, our population was at intermediate risk (average STS-PROM 6.7\%). As TAVI indications expand to include lower-risk populations, further iterative derivation/validation processes and studies will be required to validate the ACC/TVT registry risk model, as well as other models.

\section{Conclusions}

In a large, diverse population, the validation of the ACC/TVT registry risk model demonstrated good discrimination for the prediction of in-hospital mortality and was not significantly different from the STS-PROM risk score for 30-day mortality. Therefore, the ACC/TVT registry risk model should be considered as an alternative to the STS-PROM risk model to guide future risk-benefit analysis discussions in patients eligible for TAVI.

\section{Impact on daily practice}

As TAVI indications expand towards intermediate- and lowrisk patients, a reliable and easy to use risk stratification tool, dedicated and validated for TAVI patients, is of major importance in order to inform patients, discuss expectations of treatment and report results. In our study, we compared the predictive accuracy of the ACC/TVT risk score to the surgical EuroSCORE II and STS-PROM score. From the analysis of our large and diverse population of patients, the ACC/TVT registry risk model demonstrated good discrimination for the prediction of in-hospital mortality and was not significantly different from the STS-PROM risk score for 30-day mortality.

\section{Acknowledgements}

We would like to thank Matthew Brinkman and Liao Ming for their great contribution to the preparation of this manuscript.

\section{Funding}

This research study was self-funded by the Department of Cardiology of the Columbia University Medical Center \& NewYork-Presbyterian Hospital, New York, USA.

\section{Conflict of interest statement}

The authors have no conflicts of interest to declare. 


\section{References}

1. Makkar RR, Fontana GP, Jilaihawi H, Kapadia S, Pichard AD, Douglas PS, Thourani VH, Babaliaros VC, Webb JG, Herrmann HC, Bavaria JE, Kodali S, Brown DL, Bowers B, Dewey TM, Svensson LG, Tuzcu M, Moses JW, Williams MR, Siegel RJ, Akin JJ, Anderson WN, Pocock S, Smith CR, Leon MB; PARTNER Trial Investigators. Transcatheter aortic-valve replacement for inoperable severe aortic stenosis. $N$ Engl J Med. 2012;366: 1696-704.

2. Smith CR, Leon MB, Mack MJ, Miller DC, Moses JW, Svensson LG, Tuzcu EM, Webb JG, Fontana GP, Makkar RR, Williams M, Dewey T, Kapadia S, Babaliaros V, Thourani VH, Corso P, Pichard AD, Bavaria JE, Herrmann HC, Akin JJ, Anderson WN, Wang D, Pocock SJ; PARTNER Trial Investigators. Transcatheter versus surgical aortic-valve replacement in high-risk patients. N Engl J Med. 2011;364:2187-98.

3. Leon MB, Smith CR, Mack MJ, Makkar RR, Svensson LG, Kodali SK, Thourani VH, Tuzcu EM, Miller DC, Herrmann HC, Doshi D, Cohen DJ, Pichard AD, Kapadia S, Dewey T, Babaliaros V, Szeto WY, Williams MR, Kereiakes D, Zajarias A, Greason KL, Whisenant BK, Hodson RW, Moses JW, Trento A, Brown DL, Fearon WF, Pibarot P, Hahn RT, Jaber WA, Anderson WN, Alu MC, Webb JG; PARTNER 2 Investigators. Transcatheter or Surgical Aortic-Valve Replacement in Intermediate-Risk Patients. $N$ Engl J Med. 2016;374:1609-20.

4. Shahian DM, O’Brien SM, Filardo G, Ferraris VA, Haan CK, Rich JB, Normand SL, DeLong ER, Shewan CM, Dokholyan RS, Peterson ED, Edwards FH, Anderson RP; Society of Thoracic Surgeons Quality Measurement Task Force. The Society of Thoracic Surgeons 2008 cardiac surgery risk models: part 1--coronary artery bypass grafting surgery. Ann Thorac Surg. 2009;88:S2-22.

5. O'Brien SM, Shahian DM, Filardo G, Ferraris VA, Haan CK, Rich JB, Normand SL, DeLong ER, Shewan CM, Dokholyan RS, Peterson ED, Edwards FH, Anderson RP; Society of Thoracic Surgeons Quality Measurement Task Force. The Society of Thoracic Surgeons 2008 cardiac surgery risk models: part 2--isolated valve surgery. Ann Thorac Surg. 2009;88:S23-42.

6. Nashef SA, Roques F, Michel P, Gauducheau E, Lemeshow S, Salamon R. European system for cardiac operative risk evaluation (EuroSCORE). Eur J Cardiothorac Surg. 1999;16:9-13.

7. Nashef SA, Roques F, Sharples LD, Nilsson J, Smith C, Goldstone AR, Lockowandt U. EuroSCORE II. Eur J Cardiothorac Surg. 2012;41:734-44.

8. Beohar N, Whisenant B, Kirtane AJ, Leon MB, Tuzcu EM, Makkar R, Svensson LG, Miller DC, Smith CR, Pichard AD, Herrmann HC, Thourani VH, Szeto WY, Lim S, Fischbein M, Fearon WF, O’Neill W, Xu K, Dewey T, Mack M. The relative performance characteristics of the logistic European System for Cardiac Operative Risk Evaluation score and the Society of Thoracic Surgeons score in the placement of Aortic Transcatheter Valves trial. J Thorac Cardiovasc Surg. 2014;148:2830-7.

9. Durand E, Borz B, Godin M, Tron C, Litzler PY, Bessou JP, Dacher JN, Bauer F, Cribier A, Eltchaninoff H. Performance analysis of EuroSCORE II compared to the original logistic EuroSCORE and STS scores for predicting 30-day mortality after transcatheter aortic valve replacement. Am J Cardiol. 2013; 111:891-7.

10. Edwards FH, Cohen DJ, O'Brien SM, Peterson ED, Mack MJ, Shahian DM, Grover FL, Tuzcu EM, Thourani VH, Carroll J, Brennan JM, Brindis RG, Rumsfeld J, Holmes DR Jr; Steering Committee of the Society of Thoracic Surgeons/American College of Cardiology Transcatheter Valve Therapy Registry. Development and Validation of a Risk Prediction Model for In-Hospital Mortality After Transcatheter Aortic Valve Replacement. JAMA Cardiol. 2016;1:46-52.

11. TAVR In-Hospital Mortality Risk Calculator. April 14, 2016. Available at: http://tools.acc.org/tavrrisk/. Accessed 27 November 2017.

12. Online STS Adult Cardiac Surgery Risk Calculator. 2007. Available at: http://riskcalc.sts.org/stswebriskcalc/. Accessed 27 November 2017.

13. EuroSCORE Interactive Calculator. March 10, 2011. Available at: http://www.euroscore.org/calc.html. Accessed 27 November 2017.

14. Kappetein AP, Head SJ, Généreux P, Piazza N, van Mieghem NM, Blackstone EH, Brott TG, Cohen DJ, Cutlip DE, van Es GA, Hahn RT, Kirtane AJ, Krucoff MW, Kodali S, Mack MJ, Mehran R, Rodés-Cabau J, Vranckx P, Webb JG, Windecker S, Serruys PW, Leon MB; Valve Academic Research Consortium (VARC)-2. Updated standardized endpoint definitions for transcatheter aortic valve implantation: the Valve Academic Research Consortium-2 consensus document (VARC-2). Eur J Cardiothorac Surg. 2012;42:S45-60.

15. Debonnaire P, Fusini L, Wolterbeek R, Kamperidis V, van Rosendael P, van der Kley F, Katsanos S, Joyce E, Tamborini G, Muratori M, Gripari P, Bax JJ, Marsan NA, Pepi M, Delgado V. Value of the TAVI2-SCORe versus surgical risk scores for prediction of one year mortality in 511 patients who underwent transcatheter aortic valve implantation. Am J Cardiol. 2015;115: 234-42.

16. Lung B, Laouénan C, Himbert D, Eltchaninoff H, Chevreul K, Donzeau-Gouge P, Fajadet J, Leprince P, Leguerrier A, Lièvre M, Prat A, Teiger E, Laskar M, Vahanian A, Gilard M; FRANCE 2 Investigators. Predictive factors of early mortality after transcatheter aortic valve implantation: individual risk assessment using a simple score. Heart. 2014;100:1016-23.

17. Seiffert M, Sinning JM, Meyer A, Wilde S, Conradi L, VasaNicotera M, Ghanem A, Kempfert J, Hammerstingl C, Ojeda FM, Kim WK, Koschyk DH, Schirmer J, Baldus S, Grube E, Möllmann H, Reichenspurner H, Nickenig G, Blankenberg S, Diemert P, Treede H, Walther T, Werner N, Schnabel RB. Development of a risk score for outcome after transcatheter aortic valve implantation. Clin Res Cardiol. 2014;103:631-40.

18. Martin GP, Sperrin M, Ludman PF, de Belder MA, Redwood SR, Townend JN, Gunning M, Moat NE, Banning AP, Buchan I, Mamas MA. Novel United Kingdom prognostic model 
for 30-day mortality following transcatheter aortic valve implantation. Heart. 2018;104:1109-16.

19. Reardon MJ, Van Mieghem NM, Popma JJ, Kleiman NS, Søndergaard L, Mumtaz M, Adams DH, Deeb GM, Maini B, Gada H, Chetcuti S, Gleason T, Heiser J, Lange R, Merhi W, Oh JK, Olsen PS, Piazza N, Williams M, Windecker S, Yakubov SJ, Grube E, Makkar R, Lee JS, Conte J, Vang E, Nguyen H, Chang Y, Mugglin AS, Serruys PW, Kappetein AP; SURTAVI Investigators. Surgical or Transcatheter Aortic-Valve Replacement in Intermediate-Risk Patients. N Engl J Med. 2017;376:1321-31.

20. Edwards FH; TVT Registry Steering Committee. Risk Models for Transcatheter Aortic Valve Replacement. J Am Coll Cardiol. 2017;69:468.
21. Zusman O, Kornowski R, Witberg G, Lador A, Orvin K, Levi A, Assali A, Vaknin-Assa H, Sharony R, Shapira Y, Sagie A, Landes U. Transcatheter Aortic Valve Implantation Futility Risk Model Development and Validation among Treated Patients With Aortic Stenosis. Am J Cardiol. 2017;120:2241-6.

\section{Supplementary data}

Supplementary Table 1. Variables and endpoints of the ACC/TVT registry risk score, the STS-PROM risk score and the EuroSCORE II.

The supplementary data are published online at: http://www.pcronline.com/

eurointervention/137th_issue/72 


\section{Supplementary data}

Supplementary Table 1. Variables and endpoints of the ACC/TVT registry risk score, the STS-PROM risk score and the EuroSCORE II.

\begin{tabular}{|c|c|c|}
\hline TVT registry risk score - variables & $\underline{\text { STS-PROM risk score - variables }}$ & EuroSCORE II - variables \\
\hline \multirow{2}{*}{$\begin{array}{l}\text { Patient demographics: } \\
\text { Age / sex / race: American Indian or } \\
\text { Alaska native, Asian, Black or } \\
\text { African American, Hispanic, Native } \\
\text { Hawaiian or White. }\end{array}$} & $\begin{array}{l}\text { Procedure type: } \\
\text { Coronary artery bypass only / AV replacement / MV replacement / MV repair / AV } \\
\text { replacement + coronary artery bypass / MV replacement + coronary artery bypass / MV } \\
\text { repair + coronary artery bypass. }\end{array}$ & \multirow{2}{*}{$\begin{array}{l}\text { Patient-related factors: } \\
\text { Age / gender / renal impairment (a } \\
\text { GFR <85 ml/min is considered } \\
\text { impaired renal function) / } \\
\text { Extracardiac arteriopathy: Yes vs. } \\
\text { No / Poor mobility: Yes vs. No / } \\
\text { Previous cardiac surgery: Yes vs. No } \\
\text { / Chronic lung disease: Yes vs. No / } \\
\text { Active endocarditis: Yes vs. No / } \\
\text { Critical preoperative state: Yes vs. } \\
\text { No / Diabetes on insulin: Yes vs. No }\end{array}$} \\
\hline & Patient: age / sex / height (cm) / weight (kg) & \\
\hline \multirow{2}{*}{$\begin{array}{l}\text { Patient preprocedural } \\
\text { characteristics: } \\
\text { Serum creatinine in mg/dl / } \\
\text { Currently on dialysis / Procedure } \\
\text { access site: transfemoral vs. non- } \\
\text { transfemoral / NYHA Class IV: Yes } \\
\text { vs. No / Severe chronic lung disease: } \\
\text { Yes vs. No. }\end{array}$} & $\begin{array}{l}\text { Haemodynamic data - EF done: Yes vs. No / if yes: EF (\%) / Heart failure within } 2 \\
\text { weeks: Yes vs. No vs. Unknown. }\end{array}$ & \multirow{2}{*}{$\begin{array}{l}\text { Cardiac-related factors: } \\
\text { NYHA: I, II, III or IV / CCS class } 4 \\
\text { angina: Yes vs. No / LV function: } \\
\text { Good vs. moderate vs. poor vs. very } \\
\text { poor / Recent MI: Yes vs. No / } \\
\text { Pulmonary hypertension: no vs. } \\
\text { moderate vs. severe }\end{array}$} \\
\hline & $\begin{array}{l}\text { Race - Documented: Yes vs. No vs. Decline to disclose / if yes: Black / African } \\
\text { American Hispanic or Latino / Asian }\end{array}$ & \\
\hline \multirow{3}{*}{$\begin{array}{l}\text { Acuity status: } \\
\text { Procedure status: Elective vs. urgent } \\
\text { vs. emergent vs. salvage / Prior } \\
\text { cardiac arrest: Yes vs. No / Pre- } \\
\text { procedure inotropes: Yes vs. No / } \\
\text { Prior cardiogenic shock: Yes vs. No / } \\
\text { Mechanical assist device: Yes vs. } \\
\text { No. }\end{array}$} & Renal failure - Dialysis: Yes vs. No vs. Unknown / Last creat level: mg/dl & \multirow{2}{*}{$\begin{array}{l}\text { Operation-related factors: } \\
\text { Urgency: elective vs. urgency vs. } \\
\text { emergency vs. salvage / Weight of } \\
\text { the intervention: isolated CABG vs. } \\
\text { single non-CABG vs. } 2 \text { procedures } \\
\text { vs. } 3 \text { procedures / Surgery on } \\
\text { thoracic aorta: Yes vs. No. }\end{array}$} \\
\hline & $\begin{array}{l}\text { Cardiac presentation symptoms: At time of this admission: Stable angina / Unstable } \\
\text { angina / Angina equivalent / Non-ST-elevation MI /ST-elevation MI / Other / No } \\
\text { symptoms. }\end{array}$ & \\
\hline & $\begin{array}{l}\text { Cardiac symptoms - At time of surgery: Stable angina / Unstable angina / Angina } \\
\text { equivalent / Non-ST-elevation MI /ST-elevation MI / Other / No symptoms. }\end{array}$ & \\
\hline
\end{tabular}




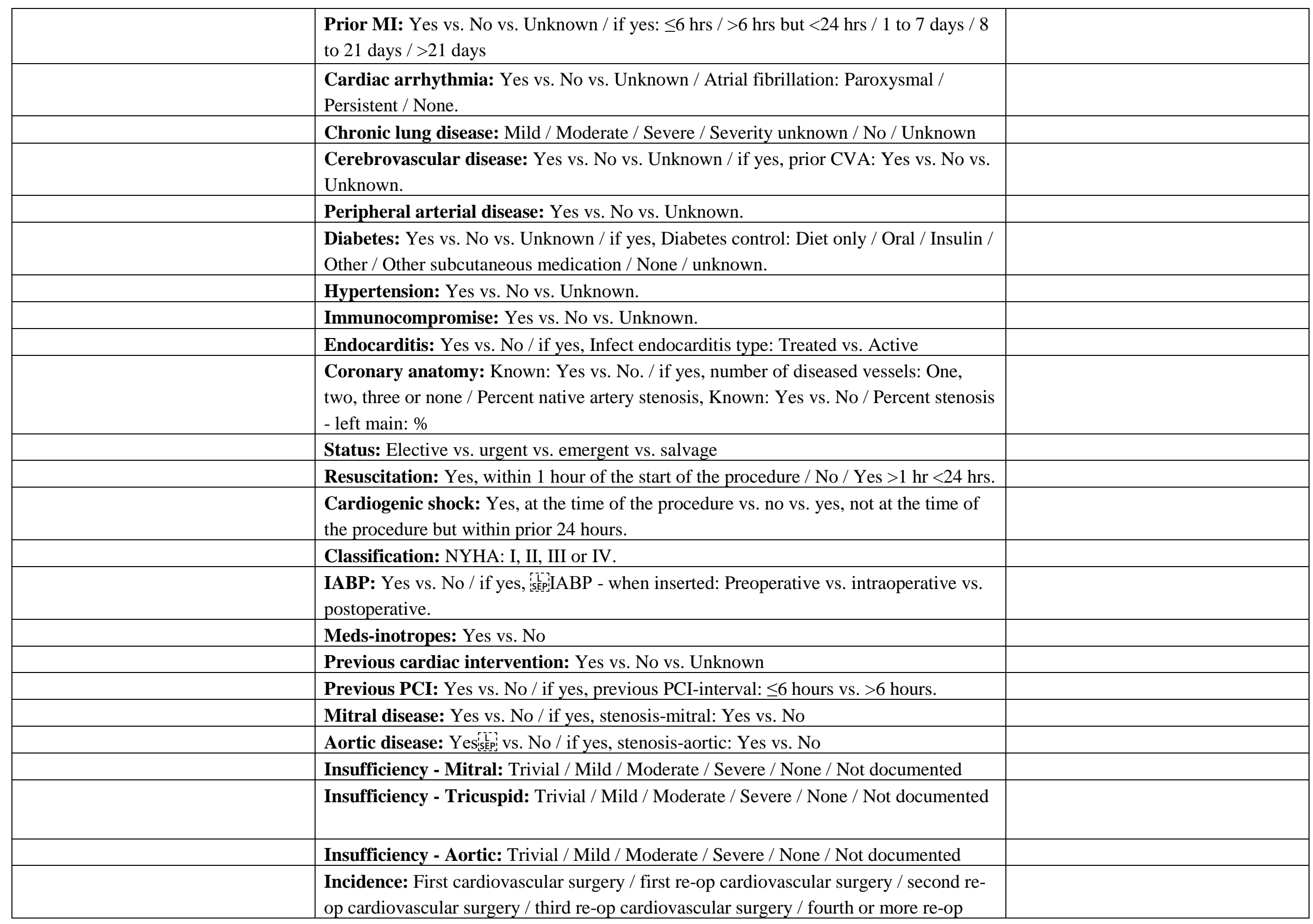




\begin{tabular}{|c|c|c|}
\hline & \multicolumn{2}{|l|}{ cardiovascular surgery } \\
\hline & \multicolumn{2}{|l|}{ Previous coronary artery bypass: Yes vs. No } \\
\hline & \multicolumn{2}{|l|}{ Previous valve surgery: Yes vs. No. } \\
\hline \multicolumn{3}{|c|}{ Endpoints: } \\
\hline Risk of in-hospital mortality & Risk of in-hospital and 30-day mortality & Risk of in-hospital mortality \\
\hline & $\begin{array}{l}\text { Morbidity or mortality: composite endpoint defined as in-hospital or } 30 \text { - } \\
\text { day mortality, deep sternal wound infection, permanent stroke, prolonged } \\
\text { ventilation, renal failure and/or reoperation. }\end{array}$ & \\
\hline & Deep sternal wound infection: in-hospital and at 30 days. & \\
\hline & \multirow{2}{*}{$\begin{array}{l}\text { Permanent stroke: any confirmed neurological deficit of abrupt onset } \\
\text { caused by a disturbance in blood supply to the brain that did not resolve } \\
\text { within } 24 \text { hours. }\end{array}$} & \\
\hline & & \\
\hline & Prolonged ventilation: $>24$ hours. & \\
\hline & $\begin{array}{l}\text { Renal failure: increase of serum creatinine to } \geq 4.0 \text { with an increase of at } \\
\text { least } 0.5 \mathrm{mg} / \mathrm{dl} \text { or } 3 x \text { most recent preoperative creatinine level. } \\
\text { A new requirement for dialysis postoperatively. }\end{array}$ & \\
\hline & Reoperation for any reason & \\
\hline & Long length of stay: $>14$ days post procedure. & \\
\hline & Short length of stay: discharged within 5 days of surgery. & \\
\hline
\end{tabular}

